\title{
Mycoplasma genitalium and Other Reproductive Tract Infections in Pregnant Women, Papua New Guinea, 2015-2017
}

Michelle J.L. Scoullar, Philippe Boeuf, Elizabeth Peach, Ruth Fidelis, Kerryanne Tokmun, Pele Melepia, Arthur Elijah, Catriona S. Bradshaw, Glenda Fehler, Peter M. Siba, Simon Erskine, Elisa Mokany, Elissa Kennedy, Alexandra J. Umbers, Stanley Luchters, Leanne J. Robinson, Nicholas C. Wong, Andrew J. Vallely, Steven G. Badman, Lisa M. Vallely, Freya J.I. Fowkes, Christopher Morgan, William Pomat, Brendan S. Crabb, James G. Beeson, Healthy Mothers Healthy Babies Study Team ${ }^{1}$

Much about the range of pathogens, frequency of coinfection, and clinical effects of reproductive tract infections (RTIs) among pregnant women remains unknown. We report on RTIs (Mycoplasma genitalium, Chlamydia trachomatis, Neisseria gonorrhoeae, Trichomonas vaginalis, Treponema pallidum subspecies pallidum, bacterial vaginosis, and vulvovaginal candidiasis) and other reproductive health indicators in 699 pregnant women in Papua New Guinea during 2015-2017. We found M. genitalium, an emerging pathogen in Papua New Guinea, in 12.5\% of participants. These infections showed no evidence of macrolide resistance. In total, $74.1 \%$ of pregnant women had $\geq 1 \mathrm{RTI}$; most of these infections were treatable. We detected sexually transmitted infections (excluding syphilis) in $37.7 \%$ of women. Our findings showed that syndromic management of infections is greatly inadequate. In total, $98.4 \%$ of women had never used barrier contraception. These findings will inform efforts to improve reproductive healthcare in Papua New Guinea.

Reproductive tract infections (RTIs), includKing sexually transmitted infections (STIs), are preventable and often curable health conditions.
Public health officials consider Chlamydia trachomatis, Neisseria gonorrhoeae, Trichomonas vaginalis, and Treponema pallidum subspecies pallidum infections to be curable diseases. An estimated 376.4 million new cases of these 4 infections occur globally in adults each year; the World Health Organization Western Pacific Region has the highest number of annual new cases, estimated at 142 million (1-3). Other RTIs, such as bacterial vaginosis (BV) and vulvovaginal candidiasis (VVC) caused by Candida albicans, are also common. However, global estimates for these diseases are less certain because of differing diagnostic methodologies for BV (4) and prevalence of commensal $C$. albicans. Current estimates suggest that $8 \%-51 \%$ of pregnant women have BV (5); $20 \%-30 \%$ of asymptomatic and $40 \%$ of symptomatic women have vaginal C. albicans infections (6). RTIs can cause substantial pain and discomfort and some patients might experience debilitating stigma from their families and communities (7). Possible complications include pelvic inflammatory disease, infertility, and increased risk for other STIs. In
Author affiliations: Burnet Institute, Melbourne, Victoria, Australia (M.J.L. Scoullar, P. Boeuf, E. Peach, R. Fidelis, K. Tokmun, P. Melepia, E. Kennedy, A.J. Umbers, S. Luchters, L.J. Robinson, F.J.I. Fowkes, C. Morgan, B.S. Crabb, J.G. Beeson); Burnet Institute, Kokopo, Papua New Guinea (M.J.L. Scoullar, P. Boeuf, E. Peach, R. Fidelis, K. Tokmun, P. Melepia, E. Kennedy, A.J. Umbers, S. Luchters, L.J. Robinson, F.J.I. Fowkes, C. Morgan, B.S. Crabb, J.G. Beeson); University of Melbourne, Melbourne (M.J.L Scoullar, P. Boeuf, C.S. Bradshaw, L.J. Robinson, F.J.I. Fowkes, C. Morgan, B.S. Crabb, J.G. Beeson); University of Papua New Guinea, Port Moresby, Papua New Guinea (A. Elijah); Melbourne Sexual Health Centre, Melbourne (C.S. Bradshaw, G. Fehler); Monash University,
Melbourne (C.S. Bradshaw, S. Luchters, L.J. Robinson, N.C. Wong, F.J.I. Fowkes, C. Morgan, B.S. Crabb, J.G. Beeson); Papua New Guinea Institute of Medical Research, Goroka, Papua New Guinea (P.M. Siba, L.J. Robinson, A. Vallely, L.M. Vallely, W. Pomat); SpeeDx Pty Ltd, Sydney, New South Wales, Australia (S. Erskine, E. Mokany); Aga Khan University, Nairobi, Kenya (S. Luchters); Ghent University, Ghent, Belgium (S. Luchters); University of New South Wales, Sydney (A. Vallely, S.G. Badman, L.M. Vallely); James Cook University, Townsville, Queensland, Australia (L.M. Vallely)

DOI: https://doi.org/10.3201/eid2703.201783

${ }^{1}$ Members of this group are listed at the end of this article. 
pregnant women, RTIs can cause miscarriage, stillbirth, preterm birth, or neonatal death, as well as serious neonatal conditions such as blindness, congenital malformations, and lifelong disability $(1,8,9)$.

Mycoplasma genitalium is increasingly understood to be a major cause of poor sexual health and is associated with pelvic inflammatory disease, cervicitis, miscarriage, and preterm birth $(10,11)$. Limited data exists on $M$. genitalium prevalence, although estimates range from $<1.0 \%$ in the general adult population to $15.9 \%$ in groups at high risk, such as female commercial sex workers $(12,13)$. In pregnant women, estimates range from $0.7 \%$ in the United Kingdom (14) to $11.9 \%$ in the Solomon Islands (15). During 2010-2019, global macrolide resistance to $M$. genitalium increased from $10 \%$ to $>50 \%$ (16). In many regions, the prevalence of M. genitalium and its susceptibility to antimicrobial drugs is unknown.

Papua New Guinea is a country in the southwestern Pacific Ocean with >8.5 million persons (17). Poor pregnancy outcomes are common in this country. Estimates are imprecise because of weaknesses in vital registry systems, but $<50 \%$ of women give birth with a skilled birth attendant (18). Ultrasound machines for gestational age assessment are largely inaccessible because of scarcity, cost, and location. The estimated prevalence of low birthweight (weight $<2.5 \mathrm{~kg}$ ) ranges from $10 \%-24 \%$ and preterm birth from $7 \%-18 \%$ (19). Papua New Guinea has a high perinatal death rate of 17 deaths/1,000 pregnancies (19). Curable STIs are common; rates of $C$. trachomatis, $N$. gonorrhoeae, $T$. vaginalis, and T. pallidum infections exceed those of other high-prevalence regions such as sub-Saharan Africa $(1,20)$. However, little to no data exists on the prevalence of M. genitalium in Papua New Guinea. We evaluated the prevalence of $M$. genitalium and other RTIs among pregnant women attending antenatal clinics in the East New Britain (ENB) province of Papua New Guinea. We also investigated molecular markers of resistance in clinical samples from these patients. We investigated the relationships between different RTIs, factors associated with infection, and analyzed the diagnostic accuracy of syndromic management guidelines.

\section{Materials and Methods}

\section{Study Site and Population}

We studied cross-sectional baseline data from 699 pregnant women attending their first antenatal clinic. Study participants were enrolled in Healthy Mothers Healthy Babies, a prospective cohort study undertaken at 5 health facilities in 3 of the 4 districts of ENB.
The study sites included the hospitals in the 2 major urban areas and the 3 largest rural health centers of ENB. Members of the largest ethnic group, the Tolai, access all facilities; members of the second largest ethnic group, the Baining, predominantly access Kerevat Rural Hospital, the government-operated rural facility. Enrollment in the Healthy Mothers Healthy Babies cohort, and thus this study, occurred during March 2015-June 2017. Women $\geq 16$ years of age who were living in the facilities' catchment area and attending clinic for the first time in the current pregnancy, regardless of gestational age, were eligible to participate. At each site, women were randomly selected through a dice roll. After the women underwent eligibility screening and provided informed consent, they completed a questionnaire administered by a trained research officer. We collected sociodemographic and clinical information through the questionnaire and patient-held medical records. We obtained urine, capillary finger prick blood, self-collected vaginal swab, and venous blood samples. We communicated all abnormal results available at the point of care, such as results of the urine dipstick and syphilis, malaria, and hemoglobin assays, to the participant and the healthcare provider.

\section{Study Procedures}

Health facility staff provided routine antenatal care, including intermittent preventive treatment in pregnancy for malaria, syndromic management for vaginal discharge (Appendix, https://wwwnc.cdc.gov/ EID/article/27/3/20-1783-App1.pdf), iron and folate supplementation, voluntary counselling and testing for HIV using Alere Determine HIV-1/2 (Abbott, https://www.abbott.com), and point-of-care syphilis testing using Alere Determine Syphilis TP (Abbott), in accordance with national guidelines $(21,22)$. At the beginning of the study period, the participating healthcare facilities conducted syphilis testing. However, interruptions in stock supply nationally led to fewer women being tested for syphilis. The research team subsequently supplied and conducted testing for study participants. Stock interruptions of HIV testing materials also occurred; however, our research team was not qualified for voluntary counselling and testing and did not have ethics approval to conduct HIV testing.

Each participant provided 2 self-collected vaginal swab samples: 1 GeneXpert vaginal/endocervical swab (Cepheid, https://www.cepheid.com), which was placed directly into its transport medium, and 1 Copan flocked swab (Copan Diagnostics, Inc., https://www.copanusa.com), which was first used 
Table 2. Prevalence of reproductive tract infections among pregnant women in East New Britain, Papua New Guinea, 2015-2017*

\begin{tabular}{|c|c|c|c|}
\hline Reproductive tract infection & Tested & Frequency & Prevalence, \% (95\% Cl) \\
\hline No current RTI† & 467 & 121 & $25.9(22-30.1)$ \\
\hline No current STI & 485 & 302 & $62.3(57.8-66.6)$ \\
\hline Mycoplasma genitalium & 625 & 78 & $12.5(10-15.3)$ \\
\hline Chlamydia trachomatis & 640 & 122 & $19.1(16.1-22.3)$ \\
\hline Neisseria gonorrhoeae & 640 & 35 & $5.5(3.8-7.5)$ \\
\hline Trichomonas vaginalis & 581 & 117 & $20.1(16.9-23.6)$ \\
\hline Syphilis§ & 437 & 79 & $18.1(14.6-22)$ \\
\hline Bacterial vaginosis & 653 & 170 & $26(22.7-29.6)$ \\
\hline Vulvovaginal candidiasis & 653 & 245 & $37.5(33.8-41.4)$ \\
\hline \multicolumn{4}{|l|}{ Co-infections } \\
\hline$\geq 1$ Current RTI & 467 & 346 & $74.1(69.9-78)$ \\
\hline$\geq 1$ Current STI & 485 & 183 & $37.7(33.4-42.2)$ \\
\hline$\geq 1 \mathrm{MG}, \mathrm{CT}, \mathrm{NG}, \mathrm{TV}$, or syphilis infection & 302 & 144 & $47.7(41.9-53.5)$ \\
\hline$\geq 1 \mathrm{MG}, \mathrm{CT}, \mathrm{NG}, \mathrm{TV}$, or BV infection & 467 & 250 & $53.5(48.9-58.1)$ \\
\hline$\geq 1$ Infection diagnosed by GeneXpertף & 546 & 175 & $32.1(28.2-36.1)$ \\
\hline$\geq 1$ Vaginal infection\# & 542 & 362 & $66.8(62.6-70.7)$ \\
\hline$\geq 1 \mathrm{BV}$ or VVC infection & 653 & 376 & $57.6(53.7-61.4)$ \\
\hline \multicolumn{4}{|l|}{ Multiple current STIs } \\
\hline 2 & 661 & 75 & $11.3(9-14)$ \\
\hline 3 & 536 & 15 & $2.8(1.6-4.6)$ \\
\hline \multicolumn{4}{|c|}{$\begin{array}{l}\text { *Participants result included only if they had all tests done for each of the infections within group of RTIs. BV, bacterial vaginosis; CT, Chlamydia } \\
\text { trachomatis; MG, Mycoplasma genitalium; NG, Neisseria gonorrhoeae; RTI, reproductive tract infection; STI, sexually transmitted infection; TV, } \\
\text { Trichomonas vaginalis; VVC, vulvovaginal candidiasis. } \\
\text { †RTIs include MG, CT, NG, TV, BC, and VVC (syphilis not included). } \\
\text { ‡STIs include MG, CT, NG, TV (syphilis not included). } \\
\text { §Diagnosed with Alere Determine Syphilis TP (Abbott, https://www.abbott.com). } \\
\text { TCT, NG, and TV infections diagnosed with GeneXpert (Cepheid, https://www.cepheid.com). } \\
\text { \#Vaginal infections include BV, TV, and VVC. }\end{array}$} \\
\hline
\end{tabular}

to prepare a vaginal smear on a slide for microscopy, and then placed in $1.0 \mathrm{~mL}$ Copan Universal Transport Medium (Copan Diagnostics, Inc.) specific for bacterial STIs. The number of vaginal swabs and smears available for diagnosis varied because of occasional reluctance to provide a swab, quality of vaginal smear, and availability of GeneXpert testing cartridges. Each woman self-collected a urine sample in a sterile container. All specimens were stored in a chilled box at $2^{\circ} \mathrm{C}-7^{\circ} \mathrm{C}$ for the remainder of clinic day, then stored at $2^{\circ} \mathrm{C}-7^{\circ} \mathrm{C}$ or $-20^{\circ} \mathrm{C}$ until tested.

\section{Laboratory Methods}

We used the GeneXpert molecular platform (Cepheid) to test vaginal and urine specimens for $C$. trachomatis, $N$. gonorrhoeae, and T. vaginalis at the Burnet Institute/ Papua New Guinea Institute of Medical Research laboratory at St. Mary's Hospital Vunapope (Kokopo, Papua New Guinea). M. genitalilum and resistance mutations were detected by quantitative PCR (ResistancePlus MG kit, SpeeDx Pty Ltd, https://plexpcr.com). Gram-stained vaginal smears were read by an experienced microscopist at the Melbourne Sexual Health Centre (Melbourne, Victoria, Australia) (Appendix).

\section{Data Management and Statistical Analysis}

Researchers interviewed participants and documented their responses using electronic tablets. We employed stringent data management protocols (Appendix).
The questionnaire included details about the enrollment clinic, participant characteristics at enrollment, and relevant obstetric history (Appendix). This study produced prevalence estimates of M. genitalium, C. trachomatis, N. gonorrhoeae, T. vaginalis, $T$. pallidum, BV, and VVC among pregnant women in Papua New Guinea. We used logistic regression to assess the association between patient characteristics and STIs, including C. trachomatis, N. gonorrhoeae, $T$. vaginalis, and M. genitalium. We included all variables of interest in the univariable analysis. The multivariable model retained variables associated with the outcome at $p<0.10$ in the univariable analysis. We also analyzed the effectiveness of syndromic management guidelines using the standard question about current symptoms compared with an alternative question about symptoms experienced during the current pregnancy.

\section{Ethics Considerations}

All participants provided individual written, informed consent. Ethics approval was provided from the Medical Research Advisory Committee of the Papua New Guinea National Department of Health (approval no. 14.27), the Papua New Guinea Institute of Medical Research Institutional Review Board (approval no. 1114), and the Human Research Ethics Committee of the Alfred Hospital in Australia (approval no. 348/14). Provincial approval was obtained 
from the East New Britain Provincial Executive Committee and participating facilities. A series of community engagement meetings provided broader community support and assent for the study.

\section{Results}

We enrolled 699 pregnant women at 5 antenatal clinics in ENB. The median maternal age was 26 years (interquartile range [IQR] 22-30 years), 25.3\% (177/699) of women were primigravida, $95.1 \%(663 / 697)$ were married or lived with a partner, and $46.5 \%(325 / 698)$ had only completed primary school (Table 1, https:/ / wwwnc.cdc.gov/EID/article/27/3/20-1783-T1. $\mathrm{htm})$. In total, $82.5 \%$ (569/690) of women had never used a modern method of contraception; only 11 $(1.6 \%)$ women had ever used a condom for men or women.

\section{High Burden of RTls During Pregnancy}

The total number of women tested for each pathogen varied as detailed in Methods. Of the 699 women enrolled, $12.5 \%$ (78/625; 95\% CI 10.0\%-15.3\%) had M. genitalium infections. We found no evidence of macrolide-resistant mutations (Table 2). Among the samples tested, 19.1\% (122/640; 95\% CI 16.1\%-22.3\%) of women had C. trachomatis infections, 5.5\% (35/640; 95\% CI 3.8\%-7.5\%) had N. gonorrhoeae infections; and $20.1 \%(117 / 581 ; 95 \%$ CI $17.0 \%-23.7 \%)$ of tested samples were positive for T. vaginalis. Lifetime exposure to syphilis was extremely high: $18.1 \%$ (79/437; 95\% CI $14.6 \%-22.0 \%$ ) of samples were positive by T. pallidum serologic testing. Among the 653 vaginal smears available for microscopy, BV prevalence was $26.0 \%$ (170/653; 95\% CI 22.7\%-29.6\%) and VVC prevalence was $37.5 \%$ (245/653; 95\% CI 33.8\%-41.4\%). Facilitybased HIV rapid test results were available for 205 women, of whom $2(0.98 \%)$ were HIV-positive.

Among women for whom all results were available, most $(74.1 \%$; 346/467) had $\geq 1$ RTI (i.e., BV, VVC, M. genitalium, C. trachomatis, $N$. gonorrhoeae, or T. vaginalis) at the time of screening; $37.7 \%(183 / 485)$ had $\geq 1$ curable STI (i.e., M. genitalium, C. trachomatis, $N$. gonorrhoeae, or T. vaginalis) at the time of screening. Among the women who were tested, 32.1\% (175/546) had an STI diagnosed using GeneXpert (C. trachomatis, N. gonorrhoeae, or T. vaginalis), $11.3 \%$ (75/661) had $\geq 2$ concurrent STIs, $2.8 \%(15 / 536)$ of women had $\geq 3$ coinfections, and 1 woman had 4 STIs.

\section{Associations between Infections}

Of the 78 women with M. genitalium infections, 28 (35.9\%) had $\geq 1$ concurrent STI detected: 20 (25.6\%) had C. trachomatis infections, $13(16.7 \%)$ had T. vaginalis infections, and $6(7.7 \%)$ had N. gonorrhoeae infections (Figure 1; Appendix Table 2). Co-infections were most frequent among women with $N$. gonorrhoeae infections (80\%; 28/35); most women with N. gonorrhoeae infections also had $C$. trachomatis infections (71.4\%; 25/35), T. vaginalis infections $(22.8 \% ; 8 / 35)$, or M. genitalium infections $(17.1 \% ; 6 / 35)$. We did not consider syphilis in estimates of coinfections because the syphilis test did not distinguish between current or previous infection. Of 170 women with BV, 40.6\% $(69 / 170)$ had a co-infection; the most common were C. trachomatis $(24.1 \% ; 41 / 170), T$. vaginalis $(12.3 \%$; $21 / 170)$, M. genitalium (12.3\%; 21/170), and N. gonorrhoeae $(7.6 \% ; 13 / 170)$ (Appendix Table 3$)$.

\section{Relationship between Abnormal Vaginal Discharge and Infection}

We compared the infections of women with current abnormal vaginal discharge (as defined by national treatment guidelines) with those who had abnormal vaginal discharge currently or at any time in pregnancy before their first antenatal clinic visit (Table 3). A total of 98 women $(14.1 \%$; 98/697) had current symptoms (i.e., abnormal vaginal discharge) that would have prompted treatment according to syndromic management guidelines (2 women did not answer this question). An additional 37 women did not have

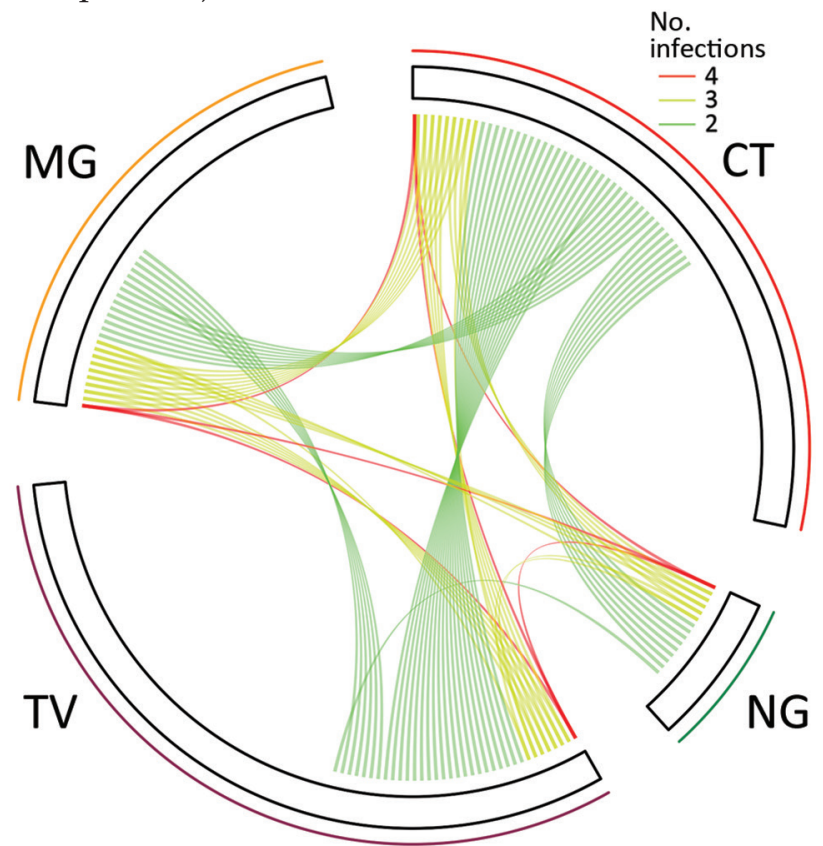

Figure 1. Relationships among sexually transmitted infections in pregnant women, East New Britain, Papua New Guinea, 2015-2017. Each line indicates $\geq 2$ concurrent infections in 1 participant. The length of each sector corresponds to the number of monoinfections. MG, Mycoplasma genitalium; CT, Chlamydia trachomatis; NG, Neisseria gonorrhoeae; TV, Trichomonas vaginalis. 
Table 3. Screening question for RTIs in pregnant women, East New Britain, Papua New Guinea, 2015-2017*

\begin{tabular}{|c|c|c|c|c|c|c|}
\hline \multirow[b]{2}{*}{ Category (22) } & \multicolumn{3}{|c|}{$\begin{array}{l}\text { Screening question as per syndromic } \\
\text { management guidelines: Do you currently } \\
\text { have any abnormal vaginal discharge? }\end{array}$} & \multicolumn{3}{|c|}{$\begin{array}{c}\text { Alternative question: Have you } \\
\text { experienced any abnormal vaginal } \\
\text { discharge earlier in the pregnancy or now? }\end{array}$} \\
\hline & No & Yes & Total & No & Yes & Total \\
\hline Total & $599(85.9)$ & $98(14.1)$ & 697 & $563(80.7)$ & $135(19.3)$ & 698 \\
\hline \multicolumn{7}{|l|}{ Reproductive tract infection } \\
\hline No current RTI† & $112(93.3)$ & $8(6.7)$ & 120 & $108(89.3)$ & $13(10.7)$ & 121 \\
\hline No current STI & $265(88.0)$ & $36(12.0)$ & 301 & $249(82.5)$ & $53(17.5)$ & 302 \\
\hline Mycoplasma genitalium & $66(84.6)$ & $12(15.4)$ & 78 & $61(78.2)$ & $17(21.8)$ & 78 \\
\hline Chlamydia trachomatis & $98(80.3)$ & $24(19.7)$ & 122 & $90(73.8)$ & $32(26.2)$ & 122 \\
\hline Neisseria gonorrhoeae & $28(80.0)$ & $7(20.0)$ & 35 & $26(74.3)$ & $9(25.7)$ & 35 \\
\hline Trichomonas vaginalis & $94(80.3)$ & $23(19.7)$ & 117 & $83(70.9)$ & $34(29.1)$ & 117 \\
\hline Syphilis§ & $68(86.1)$ & $11(13.9)$ & 79 & $65(82.3)$ & $14(17.7)$ & 79 \\
\hline Bacterial vaginosis & 146 (85.9) & $24(14.1)$ & 170 & $136(80.0)$ & $34(20.0)$ & 170 \\
\hline Vulvovaginal candidiasis & $199(81.2)$ & $46(18.8)$ & 245 & $182(74.3)$ & $63(25.7)$ & 245 \\
\hline \multicolumn{7}{|l|}{ Co-infections } \\
\hline$\geq 1$ Current RTI & $292(84.4)$ & $54(15.6)$ & 346 & $268(77.5)$ & $78(22.5)$ & 346 \\
\hline$\geq 1$ Current STI & $154(84.2)$ & $29(15.8)$ & 183 & $141(77.0)$ & $42(23.0)$ & 183 \\
\hline$\geq 1$ Infection diagnosed by GeneXpert & $141(80.6)$ & $34(19.4)$ & 175 & $127(72.6)$ & $48(27.4)$ & 175 \\
\hline$\geq 1$ Vaginal infection\# & $298(82.3)$ & $64(17.7)$ & 362 & $271(74.9)$ & $91(25.1)$ & 362 \\
\hline$\geq 1 \mathrm{BV}$ or VVC infection & $314(83.5)$ & $62(16.5)$ & 376 & $290(77.1)$ & $86(22.9)$ & 376 \\
\hline Any 2 current STIs & $58(77.3)$ & $17(22.7)$ & 75 & $53(70.7)$ & $22(29.3)$ & 75 \\
\hline \multicolumn{7}{|c|}{$\begin{array}{l}\text { *Values are frequency, no. (\%). Missing data for } 1 \text { woman who responded yes to the alternative question had a missing response to the standard } \\
\text { question. BV, bacterial vaginosis; CT, Chlamydia trachomatis; MG, Mycoplasma genitalium; NG, Neisseria gonorrhoeae; RTI, reproductive tract infection; } \\
\text { STI, sexually transmitted infection; TV, Trichomonas vaginalis; VVC, vulvovaginal candidiasis. } \\
\text { †RTIs include MG, CT, NG, TV, BC, and VVC (syphilis not included). } \\
\text { fSTIs include MG, CT, NG, TV (syphilis not included). } \\
\text { §Diagnosed with Alere Determine Syphilis TP (Abbott, https://www.abbott.com). } \\
\text { TCT, NG, and TV infections diagnosed with GeneXpert (Cepheid, https://www.cepheid.com). } \\
\text { \#Vaginal infections include BV, TV, and VVC. }\end{array}$} \\
\hline
\end{tabular}

abnormal vaginal discharge at the time of the screening but had experienced it earlier in the pregnancy. According to the national treatment guidelines, these women would not normally receive treatment.

Most STIs were asymptomatic and neither criteria (current abnormal vaginal discharge vs. current or previous abnormal vaginal discharge during this pregnancy) performed well as a marker of infection. Of those women with a detected STI, 84.1\% (154/183) had no current symptoms and $77.0 \%(141 / 183)$ had not experienced symptoms during their current pregnancy. Conversely, $12.0 \%$ (36/301) of uninfected women had current symptoms and $17.6 \%$ (53/302) had experienced symptoms during their current pregnancy. Of those with $M$. genitalium infection, only 12 women $(15.4 \% ; 12 / 78)$ would have been treated according to syndromic management guidelines used by Papua New Guinea.

Asking whether women had any symptoms during their current pregnancy was consistently more sensitive than asking about current symptoms as per the standard diagnostic question (Figure 2); however, the sensitivity of both questions was $<30 \%$ for all individual or collective pathogens. The alternative question was less specific for $\geq 1$ current STI $(82.5 \%$ $[p=0.15]$ vs. $88 \%$ [p = 0.22]; Appendix Table 4). The alternative question was best able to identify women with T. vaginalis infection $(\mathrm{p}<0.01)$ and $\operatorname{VVC}(\mathrm{p}<0.01)$
(Appendix Table 4); however, this question still missed most infections.

\section{Factors Associated with Curable STIs}

We did not identify any factors in the univariable (Appendix Table 5) or multivariable (Table 4) analysis that were associated with an increased odds of $M$. genitalium infection. The univariable analysis showed that women who were younger, in their first pregnancy, employed, single or separated, had never used a modern method of contraception, or had abnormal vaginal discharge at any time in their current pregnancy were at increased risk for certain STIs, to varying degrees of statistical significance. In the multivariable analysis, primigravida women and those 16-24 years of age had higher odds for $C$. trachomatis infection (adjusted odds ratio [aOR] 2.17, 95\% CI 1.29-3.64 [p<0.01], and aOR 3.39, 95\% CI 1.24-9.28 [p = 0.02], respectively). Primigravida women also had higher odds for N. gonorrhoeae infection (aOR 4.33, 95\% CI $1.74-10.75 ; \mathrm{p}<0.01)$. Women $16-24$ years of age had increased odds for testing positive for $\geq 1$ STI compared with women in other age groups (aOR 2.45, 95\% CI 1.17-5.16; $\mathrm{p}=0.02$ ).

\section{Discussion}

We confirmed that M. genitalium is widespread among pregnant women in Papua New Guinea, which has 


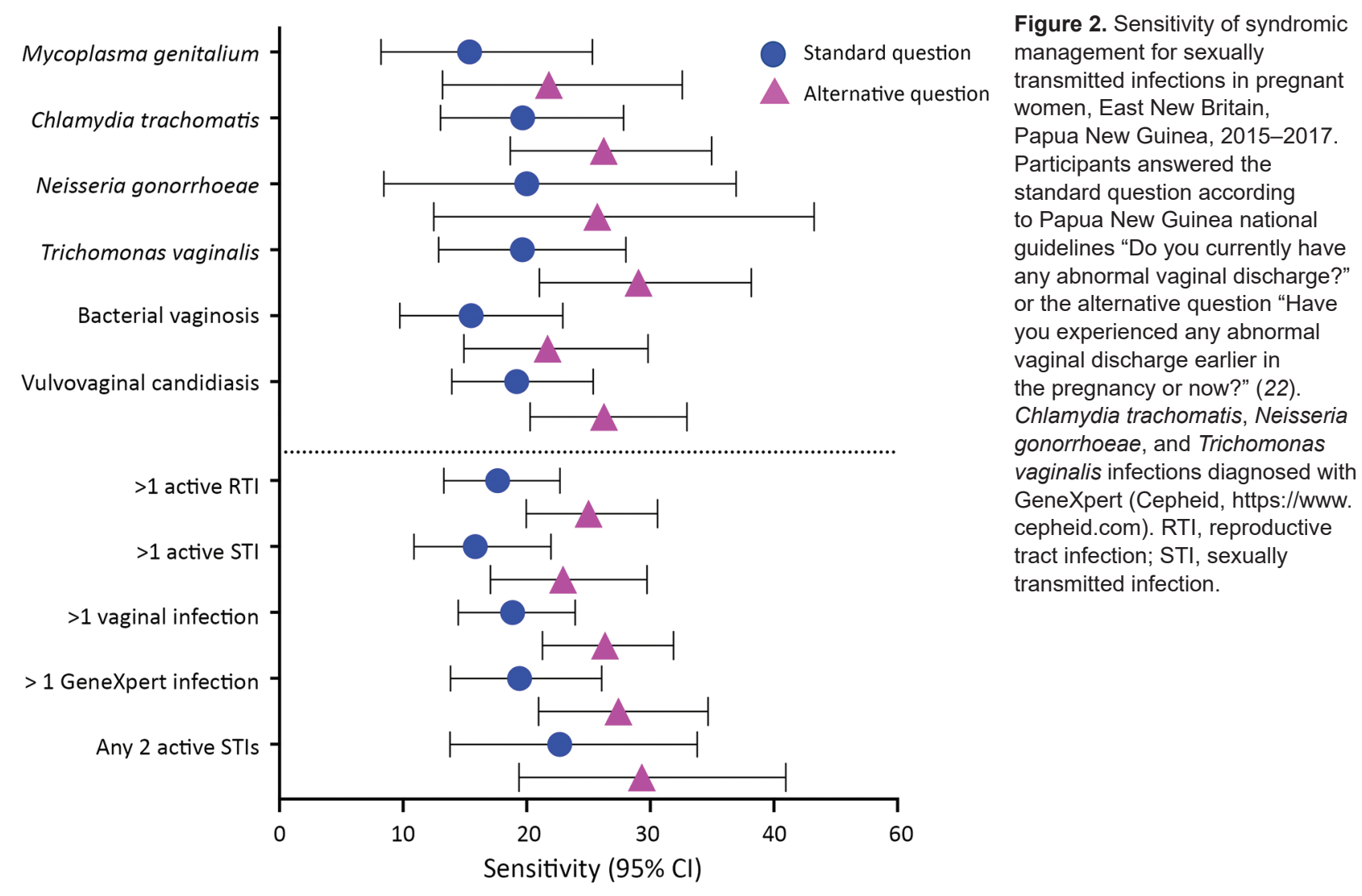

one of the highest prevalence rates of this infection globally. We did not find evidence of macrolide resistance. The high prevalence of $M$. genitalium $(12.5 \%)$ among pregnant women suggests an estimated 13,000 (95\% CI 10,342-15,823) current cases among women of reproductive age in the province (Appendix). In addition, we provide contemporary data on RTIs in pregnant women from the New Guinea Islands region of Papua New Guinea; the most recent report on the subject is $>20$ years old (23). Our study indicates that $\geq 1$ in $2(53.5 \%)$ pregnant women in ENB have a treatable RTI (including BV, STI, or both) known to cause harmful sexual and reproductive health outcomes. These RTIs are not usually detectable by the syndromic management practices described in the national health guidelines of PNG. This high prevalence of poor sexual and reproductive health has major national and regional public health significance.

No global surveillance system for M. genitalium currently exists (24). Different detection methods have varying levels of sensitivity, limiting scientific understanding of its epidemiology. High-income countries report rates of $M$. genitalium infection ranging from $0.3 \%-3.3 \%(11,13,25)$ in the general population, with higher estimates in certain populations $(26,27)$. Fewer data are available from low- and middle-income countries (LMICs) but prevalence appears to be higher, ranging from $3 \%$ in the general population in Tanzania (13) to $8 \%-9 \%$ in Honduras and South Africa $(13,28)$. The highest prevalence has been reported among sex workers: $16 \%$ in Kenya (29) and $26 \%$ in Uganda (30). Data on M. genitalium infection among pregnant women remains limited despite the disease's association with adverse pregnancy outcomes (26); available estimates range from $0.7 \%-0.9 \%$ in the United Kingdom and France $(14,31)$ to $6.2 \%$ in Guinea-Bissau (32) and $11.9 \%$ in the Solomon Islands (15). More data on the prevalence and consequences of M. genitalium infection among pregnant women are needed.

Regional data on M. genitalium in LMICs are limited. One study from the Solomon Islands examined the effects of mass drug administration (MDA) using $1 \mathrm{~g}$ of oral azithromycin for eliminating ocular C. trachomatis on M. genitalium infection rates (15). Before MDA, the study found an $11.9 \%$ (95\% CI $8.3 \%-16.6 \%$; $n=236$ ) prevalence of $M$. genitalium among pregnant women. After MDA, the prevalence remained high at $10.9 \%$ with no evidence of macrolide resistance. However, only 5 of the $28 \mathrm{M}$. genitalium-positive women in the post-MDA group had received azithromycin (15). 
In this study, the lack of macrolide resistance among $M$. genitalium infections in pregnant women warrants further exploration. Macrolide susceptibility might reflect a population's lack of exposure to this class of antimicrobial drugs. However, macrolides are used widely in Papua New Guinea $(22,33)$ and are available without prescription (although overthe-counter macrolides are more expensive than their prescribed counterparts).

We observed a prevalence of curable STIs substantially greater than in most settings included in the 2016 global estimates of curable STIs (3). The $32.1 \%$ observed prevalence of $\geq 1$ current STI diagnosable by GeneXpert is less than the $42.7 \%$ reported in a study of antenatal clinics from 3 mainland provinces of Papua New Guinea in 2014 (20), but similar to the $33.7 \%$ prevalence among pregnant women in Madang Province in 2012 (34). We found a $19.1 \%$ prevalence of $C$. trachomatis infection among pregnant women, consistent with reports from other provinces $(22.9 \%$ in the Eastern Highlands, Hela, and Central provinces [20] and 20.0\% in the Milne Bay province [35]) and the neighboring Solomon Islands (20.3\%) (36). Similarly, Papua New Guinea and Solomon Islands have the highest reported rates of N. gonorrhoeae among pregnant women $(5.1 \%-$

Table 4. Multivariable analysis of factors associated with current sexually transmitted infections in pregnant women, East New Britain, Papua New Guinea, 2015-2017*

\begin{tabular}{|c|c|c|c|c|c|}
\hline \multirow[b]{2}{*}{ Characteristic } & \multicolumn{5}{|c|}{ Sexually transmitted infection, aOR $(95 \% \mathrm{Cl}) ; \mathrm{p}$ value } \\
\hline & $\begin{array}{c}\text { Mycoplasma } \\
\text { genitalium }\end{array}$ & $\begin{array}{c}\text { Chlamydia } \\
\text { trachomatis }\end{array}$ & $\begin{array}{c}\text { Neisseria } \\
\text { gonorrhoeae }\end{array}$ & $\begin{array}{c}\text { Trichomonas } \\
\text { vaginalis }\end{array}$ & $\geq 1$ infection \\
\hline \multicolumn{6}{|l|}{ Clinic } \\
\hline Vunapope & Referent & Referent & Referent & Referent & Referent \\
\hline Nonga & $\begin{array}{c}0.68(0.28-1.62) \\
0.38\end{array}$ & $\begin{array}{c}0.88(0.43-1.78) \\
0.72\end{array}$ & $\begin{array}{c}2.35(0.76-7.32) ; \\
0.14\end{array}$ & $\begin{array}{c}0.91(0.42-1.97) \\
0.82\end{array}$ & $\begin{array}{c}0.84(0.43-1.63) ; \\
0.61\end{array}$ \\
\hline Kerevat & $\begin{array}{c}0.9(0.43-1.88) \\
0.77\end{array}$ & $\begin{array}{c}0.55(0.28-1.09) \\
0.09\end{array}$ & $\begin{array}{c}1.03(0.3-3.5) \\
0.97\end{array}$ & $\begin{array}{c}0.84(0.41-1.72) \\
0.62\end{array}$ & $\begin{array}{c}0.58(0.31-1.11) \\
0.10\end{array}$ \\
\hline Napapar & $\begin{array}{c}0.76(0.37-1.57) \\
0.46\end{array}$ & $\begin{array}{c}0.9(0.5-1.62) \\
0.73\end{array}$ & $\begin{array}{c}0.99(0.31-3.15) \\
0.98\end{array}$ & $\begin{array}{c}1.09(0.6-1.99) \\
0.77\end{array}$ & $\begin{array}{c}0.64(0.36-1.13) ; \\
0.12\end{array}$ \\
\hline Paparatava & $\begin{array}{c}0.86(0.43-1.73) \\
0.68\end{array}$ & $\begin{array}{c}0.86(0.47-1.57) \\
0.62\end{array}$ & $\begin{array}{c}2.04(0.7-5.95) \\
0.19 \\
\end{array}$ & $\begin{array}{c}1.08(0.59-1.99) \\
0.79\end{array}$ & $\begin{array}{c}1.01(0.58-1.75) ; \\
0.97\end{array}$ \\
\hline \multicolumn{6}{|l|}{ Age, y } \\
\hline $\begin{array}{l}\geq 35 \\
25-34\end{array}$ & $\begin{array}{c}\text { Referent } \\
0.76(0.34-1.69) \\
0.50\end{array}$ & $\begin{array}{c}\text { Referent } \\
2.47(0.94-6.52) \\
0.07\end{array}$ & $\begin{array}{c}\text { Referent } \\
1.01(0.2-4.98) ; \\
0.99\end{array}$ & $\begin{array}{c}\text { Referent } \\
1.85(0.78-4.37) \\
0.16\end{array}$ & $\begin{array}{c}\text { Referent } \\
1.7(0.85-3.38) ; \\
0.13\end{array}$ \\
\hline $16-24$ & $\begin{array}{c}1.21(0.52-2.82) \\
0.66\end{array}$ & $\begin{array}{c}3.39(1.24-9.28) \\
0.02\end{array}$ & $\begin{array}{c}1.86(0.36-9.63) \\
0.46\end{array}$ & $\begin{array}{c}2.31(0.93-5.7) \\
0.07\end{array}$ & $\begin{array}{c}2.45(1.17-5.16) ; \\
0.02\end{array}$ \\
\hline \multicolumn{6}{|l|}{ Gravidity } \\
\hline Multigravida & Referent & Referent & Referent & Referent & Referent \\
\hline Primigravida & $\begin{array}{c}0.87(0.46-1.65) \\
0.67\end{array}$ & $\begin{array}{c}2.17(1.29-3.64) \\
<0.01\end{array}$ & $\begin{array}{c}4.33(1.74- \\
10.75) ;<0.01\end{array}$ & $\begin{array}{c}1.09(0.62-1.92) \\
0.75\end{array}$ & $\begin{array}{c}1.45(0.87-2.42) ; \\
0.15\end{array}$ \\
\hline \multicolumn{6}{|l|}{ Marital status } \\
\hline Married/cohabiting & Referent & Referent & Referent & Referent & Referent \\
\hline Single/separated & $\begin{array}{c}1.06(0.34-3.3) \\
0.92\end{array}$ & $\begin{array}{c}1.31(0.54-3.13) ; \\
0.55\end{array}$ & $\begin{array}{c}0.44(0.09-2.23) \\
0.32\end{array}$ & $\begin{array}{c}4.48(1.9-10.55) \\
<0.01\end{array}$ & $\begin{array}{c}1.6(0.61-4.21) \\
0.34\end{array}$ \\
\hline \multicolumn{6}{|l|}{ Vaginal discharge } \\
\hline No symptoms & Referent & Referent & Referent & Referent & Referent \\
\hline $\begin{array}{l}\text { Abnormal discharge (current or } \\
\text { before first antenatal clinic) }\end{array}$ & $\begin{array}{c}1.17(0.63-2.15) \\
0.62\end{array}$ & $\begin{array}{c}1.29(0.78-2.14) \\
0.33\end{array}$ & $\begin{array}{c}1.45(0.6-3.53) \\
0.41\end{array}$ & $\begin{array}{c}1.56(0.94-2.59) \\
0.09\end{array}$ & $\begin{array}{c}1.29(0.79-2.11) \\
0.31\end{array}$ \\
\hline \multicolumn{6}{|l|}{ Has used modern contraception } \\
\hline Yes & Referent & Referent & Referent & Referent & Referent \\
\hline No & $\begin{array}{c}1.82(0.82-4.08) \\
0.14\end{array}$ & $\begin{array}{c}1.04(0.56-1.95) \\
0.90\end{array}$ & $\begin{array}{c}0.77(0.23-2.59) \\
0.67\end{array}$ & $\begin{array}{c}1.27(0.66-2.43) \\
0.47\end{array}$ & $\begin{array}{c}1.17(0.67-2.05) ; \\
0.57\end{array}$ \\
\hline \multicolumn{6}{|l|}{ Employment status } \\
\hline Unemployed & Referent & Referent & Referent & Referent & Referent \\
\hline Employed & $\begin{array}{c}0.89(0.49-1.62) \\
0.71\end{array}$ & $\begin{array}{c}1.27(0.79-2.05) \\
0.32\end{array}$ & $\begin{array}{c}2.66(1.24-5.71) \\
0.01\end{array}$ & $\begin{array}{c}0.96(0.57-1.62) \\
0.89\end{array}$ & $\begin{array}{c}1.29(0.81-2.06) ; \\
0.28\end{array}$ \\
\hline \multicolumn{6}{|l|}{ Urine nitrite } \\
\hline Trace & $\begin{array}{c}0.49(0.11-2.12) \\
0.34\end{array}$ & $\begin{array}{c}0.78(0.25-2.43) \\
0.667\end{array}$ & $\begin{array}{c}0.68(0.08-5.55) \\
0.72\end{array}$ & $\begin{array}{c}0.34(0.07-1.61) \\
0.17\end{array}$ & $\begin{array}{c}0.35(0.11-1.11) \\
0.08\end{array}$ \\
\hline Positive & $1.32(0.58-3) ; 0.50$ & $\begin{array}{c}1.88(0.94-3.74) \\
0.07\end{array}$ & $\begin{array}{c}1.6(0.5-5.09) \\
0.43\end{array}$ & $\begin{array}{c}1.29(0.6-2.76) \\
0.51\end{array}$ & $\begin{array}{c}1.26(0.62-2.58) ; \\
0.53\end{array}$ \\
\hline \multicolumn{6}{|l|}{ Fever during pregnancy } \\
\hline $\begin{array}{l}\text { No } \\
\text { Yes (before first antenatal clinic) }\end{array}$ & $\begin{array}{c}\text { Referent } \\
1.15(0.66-1.99) \\
0.63\end{array}$ & $\begin{array}{c}\text { Referent } \\
0.75(0.46-1.24) \\
0.26\end{array}$ & $\begin{array}{c}\text { Referent } \\
0.69(0.29-1.65) \\
0.41\end{array}$ & $\begin{array}{c}\text { Referent } \\
1.58(0.99-2.53) \\
0.05\end{array}$ & $\begin{array}{c}\text { Referent } \\
1(0.63-1.57) ; \\
0.99\end{array}$ \\
\hline
\end{tabular}


$14.2 \%)(34,36-38)$ in the world. In addition, 2 studies from South Africa also report very high rates of $N$. gonorrhoeae: $10.1 \%$ among patients in a primary care setting (39) and $6.4 \%$ among pregnant women (40).

Risk factors for different STIs identified in this study (e.g., primigravida, age 16-24 years, employment, being single or separated) could have several explanations. Younger women in their first pregnancy might have had less interaction with reproductive health services. Also, employed women might have more mobility, which increases risk for STI acquisition. We did not identify any risk factors for $M$. genitalium infection, although younger women (16-24 years of age) were at increased risk for $\geq 1$ of the curable current STIs. Risk factors for STIs in pregnancy reported elsewhere in Papua New Guinea include having $>1$ lifetime sexual partner, low education level of the woman or her partner, rural location, history of miscarriage or stillbirth, and low socioeconomic status $(20,34)$.

This study also provides data on BV and VVC; $57.6 \%$ of participants had $\geq 1$ of these infections. VVC can cause extreme discomfort and increase a woman's risk for postpartum breast candidiasis, which can affect breastfeeding, but VVC is treatable with antimicrobial drugs (41). We found a $37.5 \%$ prevalence of VVC, higher than the $23 \%$ prevalence reported in Papua New Guinea in 1991 (42). Comparisons with other LMICs are difficult because of the limited amount of contemporary data $(41,43)$. We found a 1-in-4 prevalence of BV among pregnant women, higher than the $17.6 \%$ prevalence previously reported in Papua New Guinea (35), but in keeping with recent global estimates of $23 \%-29 \%$ (5). However, our results might underestimate the true prevalence because diagnosis was limited to only women with a Nugent score of 7-10.

In Papua New Guinea, syndromic management of RTIs is common because access to diagnostic services is limited. We confirm previous reports from Papua New Guinea and elsewhere $(28,37)$ that syndromic management is an inadequate tool to effectively treat RTIs. This approach missed $78.2 \%$ of $M$. genitalium infections and 3 of 4 RTIs. Alternative approaches are essential to effectively prevent, detect, and treat RTIs in a cost-effective, feasible manner in resource-constrained settings. Although condoms are available, their use is limited by gender disparities, stigma, and financial barriers (23). Improved access to affordable, accurate point-ofcare diagnostics would lead to more accessible and appropriate treatment, resulting in improved sexual and reproductive health; the widespread implementation of GeneXpert for tuberculosis diagnosis (44) might also increase access to STI diagnosis in Papua New Guinea.

The main limitation of this study is the facilitybased recruitment of participants because results might not represent women who do not attend any antenatal clinic. However, routinely collected provincial data for $2015-2017$ estimated that $73 \%-85 \%$ of pregnant women attended $\geq 1$ appointment at an antenatal clinic $(45,46)$. The number of women who had a pointof-care syphilis test was lower than other tests. These results did not differentiate between active or latent infection; we also were unable to exclude exposure to yaws, which is endemic to Papua New Guinea (47). Yaws and syphilis are caused by different subspecies of T. pallidum and cannot be distinguished by this test alone. Prevalence of yaws varies widely within Papua New Guinea; estimates for ENB are unavailable, although neighboring New Ireland Province has a 1.8\% prevalence of active yaws according to a populationwide survey (48).

In conclusion, we provide data on M. genitalium prevalence and antimicrobial resistance markers in Papua New Guinea, revealing a high prevalence of infection underrecognized by syndromic management guidelines. This data contributes to the understanding of the global prevalence of this infection among pregnant women. We found that STIs were common among pregnant women; $37.7 \%$ of participants had $\geq 1$ STI at the time of the study. This study also highlights the high prevalence of BV and VVC and confirms that current antenatal screening practices with syndromic management is inadequate. This high prevalence of disease negatively affects sexual and reproductive health. Urgent action towards ensuring access to affordable prevention, diagnosis, and treatment of RTIs in communities in Papua New Guinea and similar settings is essential. This action will be crucial to achieving the sustainable development goal of ensuring universal access to sexual and reproductive healthcare services by 2030 (49). Expanding treatment access will contribute to improved sexual and reproductive health outcomes for women in Papua New Guinea.

The Healthy Mothers Healthy Babies Study Team also includes: Hadlee Supsup, Dukduk Kabiu, Priscah Hezeri, Primrose Homiehombo, Rose Suruka, Benishar Kombut, Thalia Wat, Noelyne Taraba, Chris Sohenaloe, Dorish Palangat, Zoe Saulep, Elizabeth Walep, Lucy Au, Irene Daniels, Gabriella Kalimet-Tade, Noreen Tamtilik, Ellen Kavang, Wilson Philip, Wilson Kondo, Allan Tirang, Michael Palauva, Ioni Pidian, Teddy Wanahau, and Eremas Amos. 


\section{Acknowledgments}

We extend our heartfelt thanks to the women and infants who participated in this study, as well as the families and communities who supported them to do so. Our special thanks to the National Department of Health, the East New Britain Provincial Administration, the Provincial Health Authority, Catholic Health Services, and participating health facilities (Nonga General Hospital, St Mary's Hospital Vunapope, Kerevat Rural Hospital, Napapar Health Centre, Paparatava Health Centre) for enthusiastically facilitating this research. Specific thanks to Levi Mano, Nicholas Larme, Ako Yap, Moses Bogandri, Benedict Mode, Pinip Wapi, Felix Diaku, Tanmay Bagade, Delly Babona, Placidia Nohan, Theonila Wat, and Rebecca Penaia who have provided invaluable support and advice throughout the planning and implementation of this work in East New Britain. We gratefully acknowledge the dedication and contribution by our Burnet Institute Kokopo staff who worked tirelessly to support the research team to implement this study, especially Stenard Hiasihri, Essie Koniel, Bettie Matonge, Elice Adimain, Thelma Punion, and Lucy Palom. We thank Burnet Institute Melbourne for invaluable project support, especially Kellie Woiwod, James Lawson, Lisa Davidson, Vivian Newton, Lisa Vitasovich, and Rodney Stewart. We thank our many collaborators, including Louis Samiak, Lahui Geita (deceased), Jack Richards, Suman Majumdar, Lisa Natoli, and especially John Kaldor and Rebecca Guy for advice on STIs. We also thank Michael Toole, Margaret Hellard, and Caroline Homer for their vision, overall leadership, and technical guidance to the Healthy Mothers Healthy Babies program.

This work was funded by the Burnet Institute with philanthropic support provided by numerous private and business donors in Australia andPapau New Guinea, including the Bank South Pacific PNG Community Grant, the Gras Foundation, the Finkel Foundation, the June Canavan Foundation, the Naylor Steward Ancillary Fund, and the Chrysalis Foundation. Several authors receive funding from the National Health and Medical Research Council of Australia: Senior Research Fellowship to J.G.B., Program Grant to J.G.B. and B.S.C., Career Development Fellowships to F.J.I.F. and L.J.R., Postgraduate Research Scholarship to C.M. M.J.L.S. received a Basser Research Entry Scholarship from the Royal Australasian College of Physicians Foundation (2018 and 2020). The Burnet Institute is supported by an Operational Infrastructure Grant from the State Government of Victoria, Australia, and the Independent Research Institutes Infrastructure Support Scheme of the National Health and Medical Research Council of Australia.

\section{About the Author}

Dr. Scoullar is a senior research officer at the Burnet Institute, Melbourne. Her primary research interests include infection and nutrition in pregnancy, and their subsequent effects on neonatal and infant health, especially birthweight and growth through infancy.

\section{References}

1. Newman L, Rowley J, Vander Hoorn S, Wijesooriya NS, Unemo M, Low N, et al. Global estimates of the prevalence and incidence of four curable sexually transmitted infections in 2012 based on systematic review and global reporting. PLoS One. 2015;10:e0143304. https:// doi.org/10.1371/ journal.pone.0143304

2. World Health Organization. Report on global sexually transmitted infection surveillance, 2018. 2018 [cited 2019 Dec 9]. https://www.who.int/reproductivehealth/publications/ stis-surveillance-2018

3. Rowley J, Vander Hoorn S, Korenromp E, Low N, Unemo M, Abu-Raddad LJ, et al. Chlamydia, gonorrhoea, trichomoniasis and syphilis: global prevalence and incidence estimates, 2016. Bulletin of the World Health Organization. 2019;97:548-62, 62A-62P. https://doi.org/10.2471/ BLT.18.228486

4. van de Wijgert JHHM, Jespers V. The global health impact of vaginal dysbiosis. Res Microbiol. 2017;168:859-64. https:// doi.org/10.1016/j.resmic.2017.02.003

5. Peebles K, Velloza J, Balkus JE, McClelland RS, Barnabas RV. High global burden and costs of bacterial vaginosis: a systematic review and meta-analysis. Sex Transm Dis. 2019;46:304-11. https://doi.org/10.1097/ OLQ.0000000000000972

6. Cauchie M, Desmet S, Lagrou K. Candida and its dual lifestyle as a commensal and a pathogen. Res Microbiol. 2017;168:80210. https:// doi.org/10.1016/j.resmic.2017.02.005

7. Donovan B. Sexually transmissible infections other than HIV. Lancet. 2004;363:545-56. https:/ / doi.org/10.1016/ S0140-6736(04)15543-8

8. Arol OA, Over M, Manhard L, Holmes KK. Sexually transmitted infections. In: Jamison DT, Breman JG, Measham AR, Alleyne G, Claeson M, Evans DB, et al., editors. Disease control priorities in developing countries. 2nd ed. New York: Oxford University Press; 2006. p. 315

9. Thwaites A, Flanagan K, Datta S. Non-HIV sexually transmitted infections in pregnancy. Obstet Gynaecol Reprod Med. 2019;29:151-7. https:/ / doi.org/10.1016/ j.ogrm.2019.03.001

10. Martin DH, Manhart LE, Workowski KA. Mycoplasma genitalium from basic science to public health: summary of the results from a National Institute of Allergy and Infectious Diseases Technical Consultation and Consensus Recommendations for Future Research Priorities. J Infect Dis. 2017;216:S427-30. https:/ / doi.org/10.1093/infdis/jix147

11. Lis R, Rowhani-Rahbar A, Manhart LE. Mycoplasma genitalium infection and female reproductive tract disease: a meta-analysis. Clin Infect Dis. 2015;61:418-26. https://doi.org/10.1093/cid/civ312

12. Sonnenberg P, Ison CA, Clifton S, Field N, Tanton C, Soldan K, et al. Epidemiology of Mycoplasma genitalium in British men and women aged 16-44 years: evidence from the third National Survey of Sexual Attitudes and Lifestyles (Natsal-3). Int J Epidemiol. 2015;44:1982-94. https:/ / doi.org/ 10.1093/ije/dyv194 
13. Baumann L, Cina M, Egli-Gany D, Goutaki M, Halbeisen FS, Lohrer G-R, et al. Prevalence of Mycoplasma genitalium in different population groups: systematic review and meta-analysis. Sex Transm Infect. 2018;94:255-62. https://doi.org/10.1136/sextrans-2017-053384

14. Oakeshott P, Hay P, Taylor-Robinson D, Hay S, Dohn B, Kerry S, et al. Prevalence of Mycoplasma genitalium in early pregnancy and relationship between its presence and pregnancy outcome. BJOG. 2004;111:1464-7. https:/ / doi.org/10.1111/j.1471-0528.2004.00276.x

15. Harrison MA, Harding-Esch EM, Marks M, Pond MJ, Butcher R, Solomon AW, et al. Impact of mass drug administration of azithromycin for trachoma elimination on prevalence and azithromycin resistance of genital $\mathrm{Myco-}$ plasma genitalium infection. Sex Transm Infect. 2019;95:522-8. https:/ / doi.org/10.1136/sextrans-2018-053938

16. Machalek DA, Tao Y, Shilling H, Jensen JS, Unemo M, Murray G, et al. Prevalence of mutations associated with resistance to macrolides and fluoroquinolones in Mycoplasma genitalium: a systematic review and meta-analysis. Lancet Infect Dis. 2020;20:1302-14. https://doi.org/10.1016/ S1473-3099(20)30154-7

17. The World Bank Group. Papua New Guinea. 2019 [cited 2020 Feb 25]. https:/ / data.worldbank.org/country/ papua-new-guinea

18. National Statistical Office of Papua New Guinea; ICF International, Inc. Papua New Guinea demographic and health survey 2016-18. 2019 [cited 2020 Aug 10]. https://www.nso.gov.pg/census-surveys/demographicand-health-survey

19. Robbers G, Vogel JP, Mola G, Bolgna J, Homer CSE. Maternal and newborn health indicators in Papua New Guinea-2008-2018. Sex Reprod Health Matters. 2019;27:52. https://doi.org/10.1080/26410397.2019.1686199

20. Vallely LM, Toliman P, Ryan C, Rai G, Wapling J, Tomado C, et al. Prevalence and risk factors of Chlamydia trachomatis, Neisseria gonorrhoeae, Trichomonas vaginalis and other sexually transmissible infections among women attending antenatal clinics in three provinces in Papua New Guinea: a cross-sectional survey. Sex Health. 2016;13:420-7. https://doi.org/10.1071/SH15227

21. Mola G, Amoa A, Bagita M, Augerea L, Geita L, O'Connor M. Manual of standard managements in obstetrics and gynaecology for doctors, HEOs and nurses in Papua New Guinea. 7th ed. Port Moresby (Papua New Guinea): World Health Organization; 2016. p. 10, 94.

22. National Department of Health. Standard treatment guidelines for common illness of adults in Papua New Guinea. 6th ed. Port Moresby (Papua New Guinea): World Health Organization; 2012. p. 41-2.

23. Vallely A, Page A, Dias S, Siba P, Lupiwa T, Law G, et al. The prevalence of sexually transmitted infections in Papua New Guinea: a systematic review and meta-analysis. PLoS One. 2010;5:e15586. https://doi.org/10.1371/journal. pone. 0015586

24. Golden MR, Workowski KA, Bolan G. Developing a public health response to Mycoplasma genitalium. J Infect Dis. 2017;216:S420-6. https://doi.org/10.1093/infdis/jix200

25. Jensen JS, Cusini M, Gomberg M, Moi H. 2016 European guideline on Mycoplasma genitalium infections. J Eur Acad Dermatol Venereol. 2016;30:1650-6. https://doi.org/10.1111/jdv.13849

26. Donders GGG, Ruban K, Bellen G, Petricevic L. Mycoplasma/ureaplasma infection in pregnancy: to screen or not to screen. J Perinat Med. 2017;45:505-15. https:/ / doi.org/10.1515/.jpm-2016-0111
27. Deborde M, Pereyre S, Puges M, Bébéar C, Desclaux A, Hessamfar M, et al. High prevalence of Mycoplasma genitalium infection and macrolide resistance in patients enrolled in HIV pre-exposure prophylaxis program. Med Mal Infect. 2019;49:347-9. https:/ / doi.org/10.1016/ j.medmal.2019.03.007

28. Hoffman CM, Mbambazela N, Sithole P, Morré SA, Dubbink JH, Railton J, et al. Provision of sexually transmitted infection services in a mobile clinic reveals high unmet need in remote areas of South Africa: a cross-sectional study. Sex Transm Dis. 2019;46:206-12. https:// doi.org/10.1097/OLQ.0000000000000931

29. Cohen CR, Nosek M, Meier A, Astete SG, Iverson-Cabral S, Mugo NR, et al. Mycoplasma genitalium infection and persistence in a cohort of female sex workers in Nairobi, Kenya. Sex Transm Dis. 2007;34:274-9. https:/ / doi.org/ 10.1097/01.olq.0000237860.61298.54

30. Vandepitte J, Muller E, Bukenya J, Nakubulwa S, Kyakuwa N, Buvé A, et al. Prevalence and correlates of Mycoplasma genitalium infection among female sex workers in Kampala, Uganda. J Infect Dis. 2012;205:289-96. https://doi.org/10.1093/infdis/jir733

31. Peuchant O, Le Roy C, Desveaux C, Paris A, Asselineau J, Maldonado C, et al. Screening for Chlamydia trachomatis, Neisseria gonorrhoeae, and Mycoplasma genitalium should it be integrated into routine pregnancy care in French young pregnant women? Diagn Microbiol Infect Dis. 2015;82:14-9. https://doi.org/10.1016/j.diagmicrobio.2015.01.014

32. Labbé AC, Frost E, Deslandes S, Mendonça AP, Alves AC, Pépin J. Mycoplasma genitalium is not associated with adverse outcomes of pregnancy in Guinea-Bissau. Sex Transm Infect. 2002;78:289-91. https:/ / doi.org/10.1136/sti.78.4.289

33. Joshua IB, Passmore PR, Sunderland BV. An evaluation of the Essential Medicines List, Standard Treatment Guidelines and prescribing restrictions, as an integrated strategy to enhance quality, efficacy and safety of and improve access to essential medicines in Papua New Guinea. Health Policy Plan. 2016;31:538-46. https:/ / doi.org/10.1093/heapol/ czv083

34. Wangnapi RA, Soso S, Unger HW, Sawera C, Ome M, Umbers AJ, et al. Prevalence and risk factors for Chlamydia trachomatis, Neisseria gonorrhoeae and Trichomonas vaginalis infection in pregnant women in Papua New Guinea. Sex Transm Infect. 2015;91:194-200. https:/ / doi.org/10.1136/ sextrans-2014-051670

35. Badman SG, Vallely LM, Toliman P, Kariwiga G, Lote B, Pomat $\mathrm{W}$, et al. A novel point-of-care testing strategy for sexually transmitted infections among pregnant women in high-burden settings: results of a feasibility study in Papua New Guinea. BMC Infect Dis. 2016;16:250. https://doi.org/10.1186/s12879-016-1573-4

36. Marks M, Kako H, Butcher R, Lauri B, Puiahi E, Pitakaka R, et al. Prevalence of sexually transmitted infections in female clinic attendees in Honiara, Solomon Islands. BMJ Open. 2015;5:e007276. https://doi.org/10.1136/ bmjopen-2014-007276

37. Vallely LM, Toliman P, Ryan C, Rai G, Wapling J, Gabuzzi J, et al. Performance of syndromic management for the detection and treatment of genital Chlamydia trachomatis, Neisseria gonorrhoeae and Trichomonas vaginalis among women attending antenatal, well woman and sexual health clinics in Papua New Guinea: a cross-sectional study. BMJ Open. 2017;7:e018630. https:/ / doi.org/10.1136/ bmjopen-2017-018630

38. Unger HW, Ome-Kaius M, Wangnapi RA, Umbers AJ, Hanieh S, Suen CSNLW, et al. Sulphadoxine-pyrimethamine 
plus azithromycin for the prevention of low birthweight in Papua New Guinea: a randomised controlled trial. BMC Med. 2015;13:9. https:/ / doi.org/10.1186/s12916-014-0258-3

39. Peters RPH, Dubbink JH, van der Eem L, Verweij SP, Bos MLA, Ouburg S, et al. Cross-sectional study of genital, rectal, and pharyngeal chlamydia and gonorrhea in women in rural South Africa. Sex Transm Dis. 2014;41:564-9. https://doi.org/10.1097/OLQ.0000000000000175

40. Moodley D, Moodley P, Sebitloane M, Soowamber D, McNaughton-Reyes HL, Groves AK, et al. High prevalence and incidence of asymptomatic sexually transmitted infections during pregnancy and postdelivery in KwaZulu Natal, South Africa. Sex Transm Dis. 2015;42:43-7. https://doi.org/10.1097/OLQ.0000000000000219

41. Pappas PG, Kauffman CA, Andes D, Benjamin DK Jr, Calandra TF, Edwards JE Jr, et al.; Infectious Diseases Society of America. Clinical practice guidelines for the management of candidiasis: 2009 update by the Infectious Diseases Society of America. Clin Infect Dis. 2009;48:503-35. https://doi.org/10.1086/596757

42. Klufio CA, Amoa AB, Delamare O, Hombhanje M, Kariwiga G, Igo J. Prevalence of vaginal infections with bacterial vaginosis, Trichomonas vaginalis and Candida albicans among pregnant women at the Port Moresby General Hospital Antenatal Clinic. P N G Med J. 1995;38:163-71.

43. Sobel JD. Vulvovaginal candidosis. Lancet. 2007;369:1961-71. https://doi.org/10.1016/S0140-6736(07)60917-9

44. Lavu EK, Johnson K, Banamu J, Pandey S, Carter R, Coulter $\mathrm{C}$, et al. Drug-resistant tuberculosis diagnosis since Xpert MTB/RIF introduction in Papua New Guinea, 2012-2017. Public Health Action. 2019;9:S12-8.

https://doi.org/10.5588/pha.19.0005

45. Papua New Guinea National Department of Health. Sector performance annual review. Port Moresby (Papua New Guinea): Ministry of Health; 2018.

46. Papua New Guinea National Department of Health. Sector performance annual review. Port Moresby (Papua New Guinea): Ministry of Health; 2016.

47. Mitjà O, Marks M, Konan DJP, Ayelo G, Gonzalez-Beiras C, Boua B, et al. Global epidemiology of yaws: a systematic review. Lancet Glob Health. 2015;3:e324-31. https:/ / doi.org/10.1016/S2214-109X(15)00011-X

48. Mitjà O, Godornes C, Houinei W, Kapa A, Paru R, Abel H, et al. Re-emergence of yaws after single mass azithromycin treatment followed by targeted treatment: a longitudinal study. Lancet. 2018;391:1599-607. https:/ / doi.org/10.1016/ S0140-6736(18)30204-6

49. United Nations. SDG indicators: global indicator framework for the Sustainable Development Goals and targets of the 2030 Agenda for Sustainable Development. 2021 [cited 2021 Jan 14]. https://unstats.un.org/sdgs/indicators/ indicators-list

Address for correspondence: Michelle Scoullar or James

Beeson, Burnet Institute, 85 Commercial Road, Melbourne,

VIC 3004, Australia; email: michelle.scoullar@burnet.edu.au or beeson@burnet.edu.au

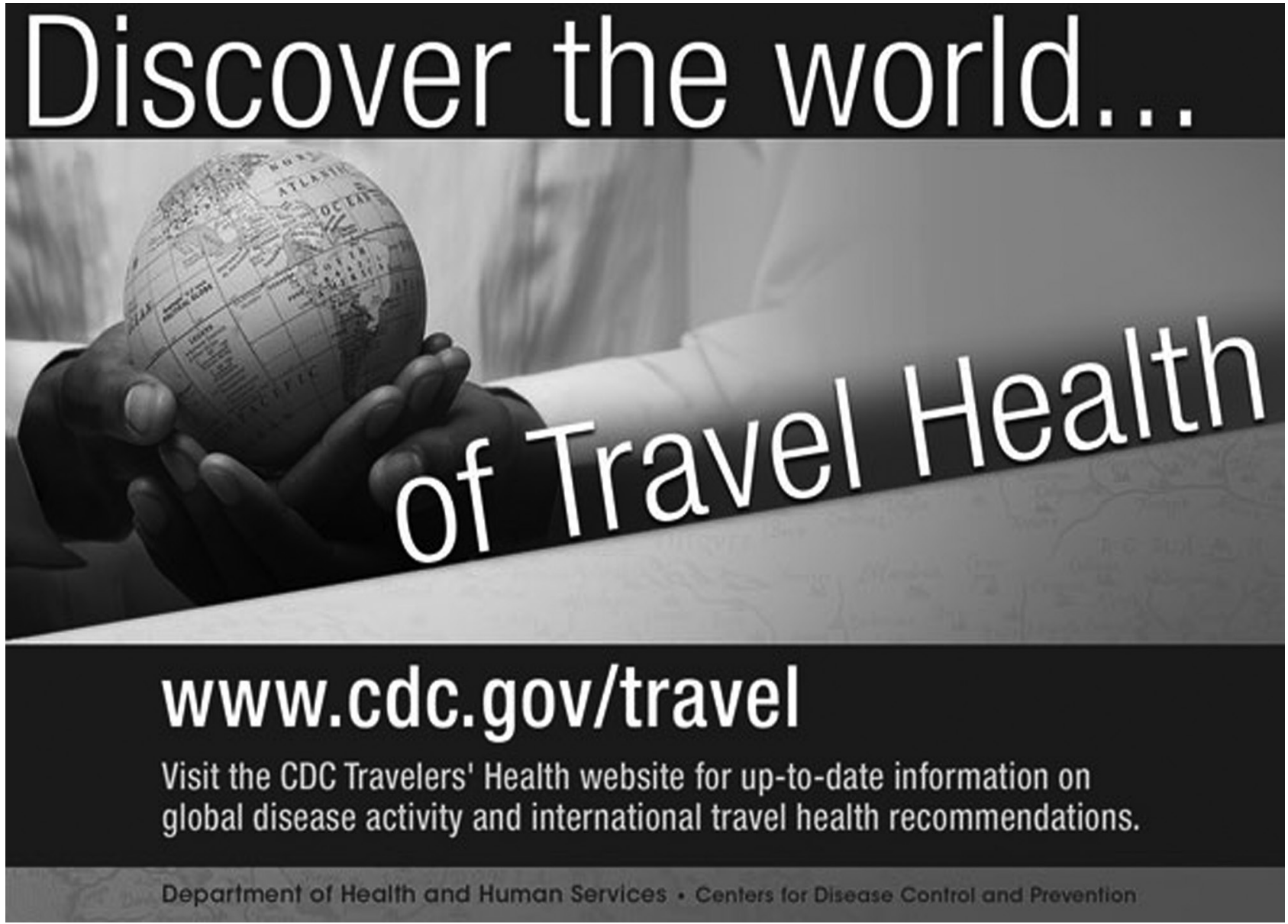

